\title{
Skin Cancer: Epidemiology, Disease Burden, Pathophysiology, Diagnosis, and Therapeutic Approaches
}

\author{
Zoe Apalla $\cdot$ Dorothée Nashan $\cdot$ Richard B. Weller $\cdot$ Xavier Castellsagué
}

Received: August 11, 2016

(C) The Author(s) 2017. This article is published with open access at Springerlink.com

\begin{abstract}
Skin cancer, including both melanoma and non-melanoma, is the most common type of malignancy in the Caucasian population. Firstly, we review the evidence for the observed increase in the incidence of skin cancer over recent decades, and investigate whether this is a true increase or an artefact of greater screening and over-diagnosis.
\end{abstract}

Dr Castellsagué very sadly passed away during the development of this article. However, given his involvement in the preparation and delivery of his presentation at the 9th Skin Academy Symposium, and his initial guidance on the content of this article, he has been included as a posthumous author at the request of his co-authors and Professor Blume-Peytavi.

Enhanced content To view enhanced content for this article go to http://www.medengine.com/Redeem/ 6C47F0600685C21C.

\section{Z. Apalla (ه)}

First Department of Dermatology, Aristotle

University of Thessaloniki, Thessaloniki, Greece

e-mail: zoimd@yahoo.gr

D. Nashan

Teaching Hospital of the University of Münster,

Münster, Germany

R. B. Weller

University of Edinburgh, Edinburgh, UK

X. Castellsagué

Catalan Institute of Oncology (ICO), L'Hospitalet de

Llobregat, Catalonia, Spain
Prevention strategies are also discussed. Secondly, we discuss the complexities and challenges encountered when diagnosing and developing treatment strategies for skin cancer. Key case studies are presented that highlight the practic challenges of choosing the most appropriate treatment for patients with skin cancer. Thirdly, we consider the potential risks and benefits of increased sun exposure. However, this is discussed in terms of the possibility that the avoidance of sun exposure in order to reduce the risk of skin cancer may be less important than the reduction in all-cause mortality as a result of the potential benefits of increased exposure to the sun. Finally, we consider common questions on human papillomavirus infection.

Keywords: Dermatology; Diagnosis; Disease burden; Epidemiology; Skin cancer; Therapy; Treatment

\section{EVOLVING EPIDEMIOLOGY AND BURDEN OF SKIN CANCER}

\section{The Increasing Incidence of Skin Cancer}

\section{Overall Skin Cancer}

Skin cancer, including both malignant melanoma (MM) and non-melanoma skin 
cancer (NMSC), represents the most common malignancy in Caucasians [1-10]. The incidence of both MM and NMSC is on the rise, with an annual increase in $\mathrm{MM}$ of $0.6 \%$ among adults over 50 years [11]. The estimated number of new cases of skin melanoma in 2016 is 76,380, which represents $4.5 \%$ of all new cancer cases [12]. Deviations in reported incidence rates exist and are attributed to varying risk factors amongst different populations, as well as discrepancies in national registration systems. Furthermore, the incidence of melanoma may be even higher than indicated, as the National Cancer Registries has reported an underestimation of its incidence in certain countries [13].

Melanoma The increased incidence of melanoma has not been accompanied by a corresponding increase in mortality rates [12]. This has led to the question of whether there is a true melanoma epidemic, or if the increased incidence represents an epiphenomenon attributable to over-diagnosis resulting from intense screening and more biopsies.

The increased incidence of melanoma in the USA involves all thickness groups (American Joint Committee on Cancer tumor categories) and is independent of socio-economic status (a surrogate marker for access to care and screening), suggesting that increased screening and biopsy alone cannot account for the dramatic change observed [14, 15]. This finding is in agreement with the results reported by Shaikh et al., who showed that thickness increased in T3/T4 tumors and nodular melanoma [16]. These observations together "suggest that the melanoma epidemic is real and not simply an artefact of increased detection pressure of earlier-stage T1/T2 lesions" [16].

Conversely, there is evidence that over-diagnosis may have a part to play. Recent epidemiologic studies indicate that melanoma in situ, with an annual incidence of 9.5\% [12], occupies a disproportionately high percentage of the overall increase in MM incidence [17]. From the dermatopathologic point of view, there are studies suggesting a current trend towards reclassification of prior non-malignant diagnoses as MM [18]. Furthermore, in a population-based study correlating the number of skin biopsies and the incidence of $\mathrm{MM}$, the investigators noted that there was a parallel increase during a 15-year period, suggesting that the MM epidemic may also be related to increased scrutiny and number of biopsies [19].

Non-Melanoma Skin Cancer NMSC includes, amongst others, Bowen's disease, basal cell carcinoma (BCC), and squamous cell carcinoma (SCC). In Caucasians, the incidence of NMSC is higher (by as much as 18-20 times) than that of MM [20-22]. However, there are significant limitations to NMSC epidemiology, mainly attributed to marked geographic variations in incidence rates, as well as to exclusion of NMSC by large cancer registries due to low mortality rates. Even secondary analyses, whereby incidence data are extracted from administrative healthcare databases, are comparatively limited [23].

NMSC carries a substantial economic burden $[24,25]$. In Australia, it is the most costly cancer, accounting for expenditure of AUS\$511 million in 2010 [24]. In the USA, it has been estimated that total annual NMSC-related expenditure is US\$650 million, with Medicare costs 6-7 times greater than those for treating melanoma [26].

\section{Reasons for Increased Incidence of Skin Cancer}

The observed increases in skin cancer rates are associated with several factors, including the transition toward significantly older populations that are associated with a higher risk of NMSC [27]. However, research has also revealed the important role of increased occupational and recreational UV light exposure $[22,28]$. For example, women $<40$ years exhibited a constant linear increase in BCC incidence rates of $6.3 \%$ between 1973 and 2009 [29], and studies have shown that indoor tanning is associated with a significantly increased risk of BCC and SCC, with a higher risk with use in early life $(<25$ years) $[30]$. 


\section{DIAGNOSTIC AND THERAPEUTIC APPROACHES TO SKIN CANCER: CHALLENGING CLINICAL CASES}

\section{Skin Cancer Diagnosis}

A diagnosis of skin cancer needs consideration of alternative diagnoses. Concerning actinic keratosis, benign conditions include seborrheic keratosis, verruca vulgaris, actinic porokeratosis, O'Brien's actinic granuloma, eczema, lentigo solaris, lichen planus, or psoriasis (Figs. 1, 2, 3), whereas malignant conditions include SCC, Bowen's disease, BCC, lentigo maligna, keratoacanthoma, or extramammary Paget's disease.

Clinicians should ideally perform total body skin examination (see Fig. 4 as an example case of actinic keratosis appearing on the back of the hand, as is often overlooked), at least for high-risk individuals [31, 32]. The use of non-invasive optical technologies, such as optical coherence tomography (non-invasive imaging test of the retina using light waves) or dermatoscopy (imaging of the skin, allowing statements concerning thickening of layers, epidermal organization, and borders of a lesion-in the case of actinic keratosis, the typical honeycomb pattern may be observed), may be helpful to improve diagnostic accuracy in some skin cancers [33-37] (the case presented in Fig. 5 may have benefitted from such technologies, for example). Photodynamic visualization (fluorescent visualization of skin cancerization extension after preparation with 5-aminolaevulinic acid and subjection to photodynamic therapy [light exposure]) might also be beneficial for identification of actinic keratosis, with histologic confirmation also being necessary in cases in which invasive skin cancer is suspected [38].

\section{Treatment Challenges}

Treatment strategies for skin cancers require careful consideration, and there are many challenges to overcome. However, with increasing treatment choices, in terms of both therapy combinations and sequences, we can achieve better outcomes for patients with fewer recurrences and longer treatment-free periods.

\section{Field Cancerization and Non-Melanoma Skin Cancer}

Field cancerization of the skin, by which large areas are affected by carcinogenic alternations, presents various therapeutic challenges (Fig. 6).

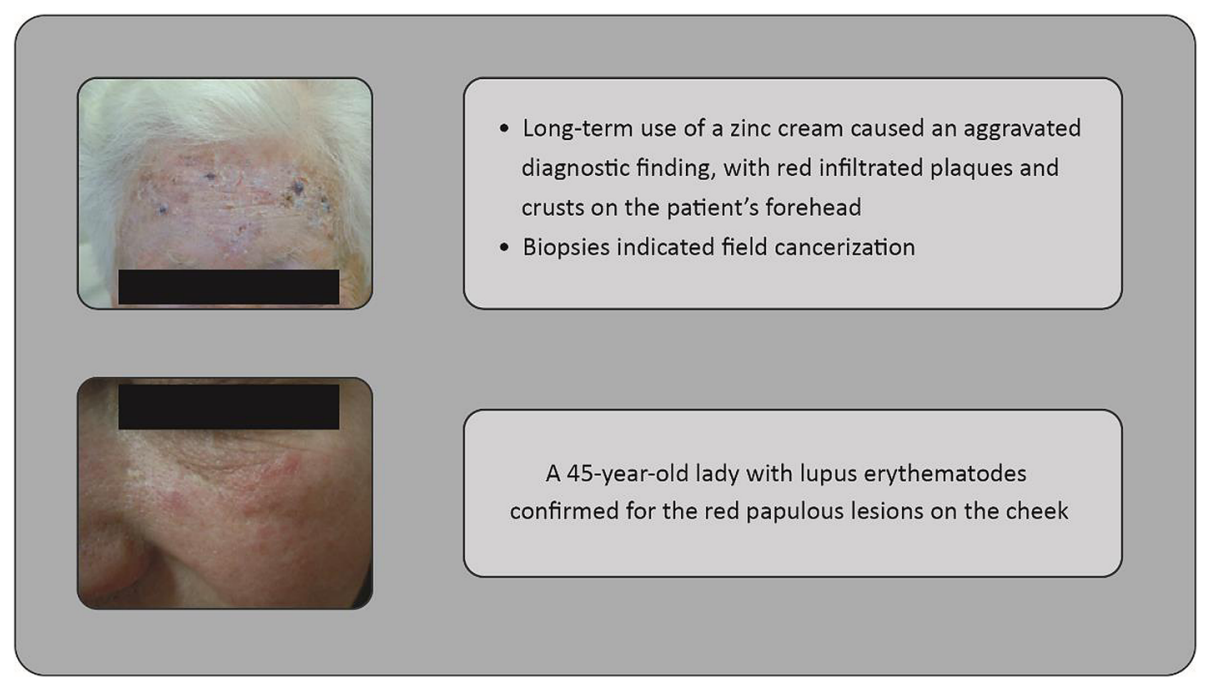

Fig. 1 Case studies: 80-year-old woman presenting with field cancerization, and 45-year-old woman presenting with lupus erythematodes (forehead and cheek shown) 


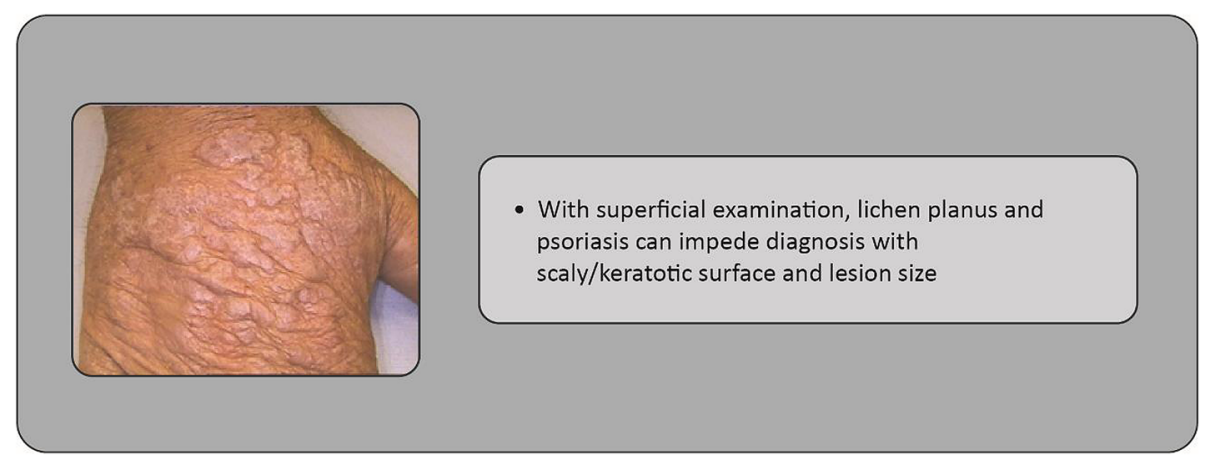

Fig. 2 Case study: lichen planus complicating diagnosis in a 78-year-old man with actinic keratosis on his hand

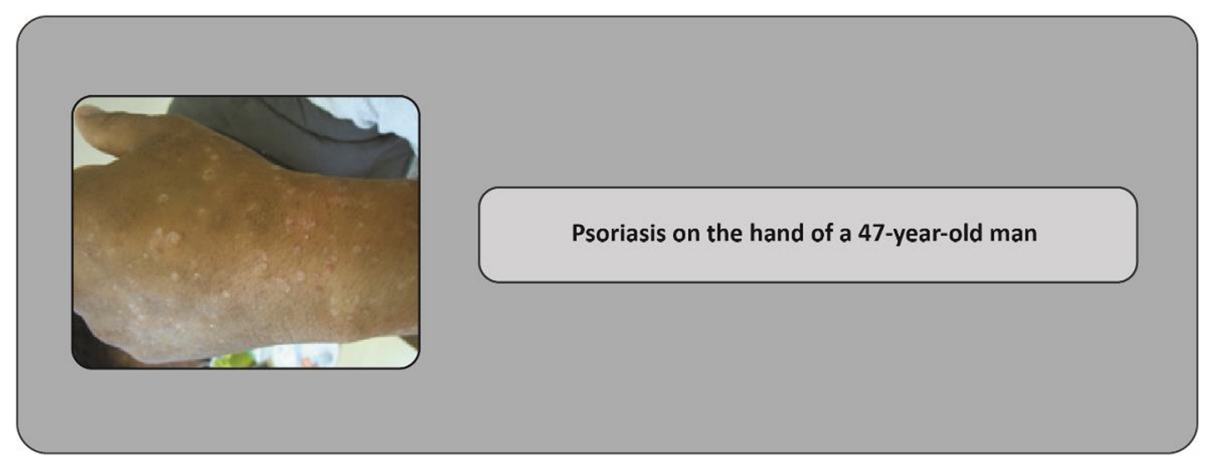

Fig. 3 Case study: psoriasis complicating diagnosis in a 47-year-old man with actinic keratosis on his hand

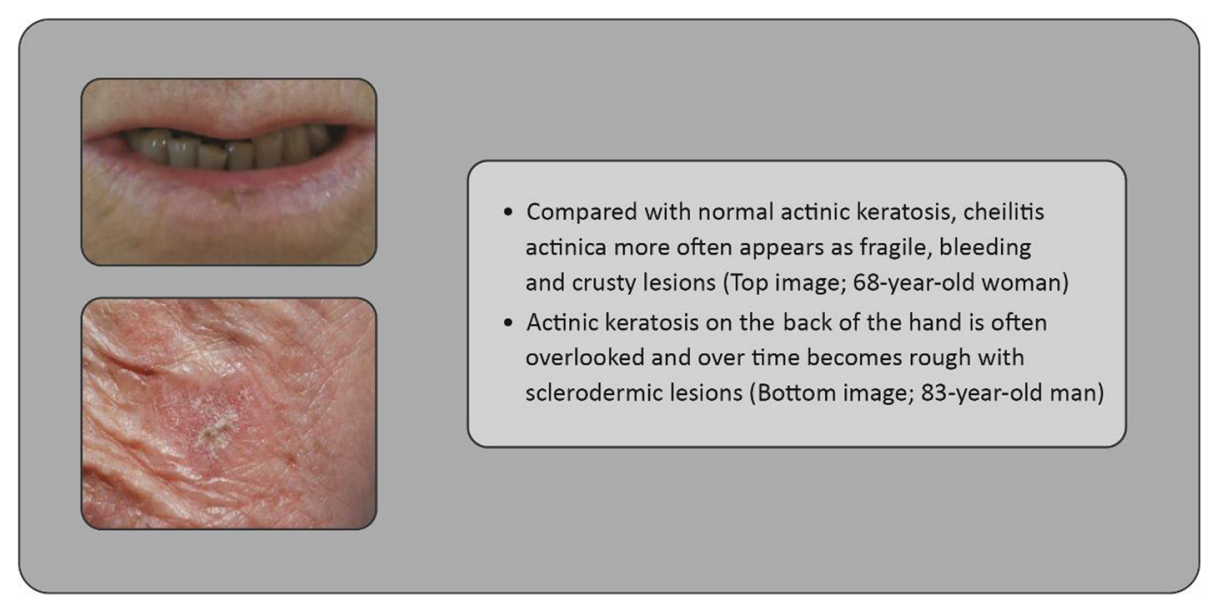

Fig. 4 Case study: cheilitis actinica versus actinic keratosis (mouth and cheek shown)

Owing to the difficulty in determining which actinic keratosis lesions may progress to invasive SCC, European guidelines recommend that all lesions, or the affected field, are treated [39]. For a patient with actinic keratosis, there are three evolutionary possibilities: spontaneous clearing; persistence; or progression to invasive SCC [40]. 


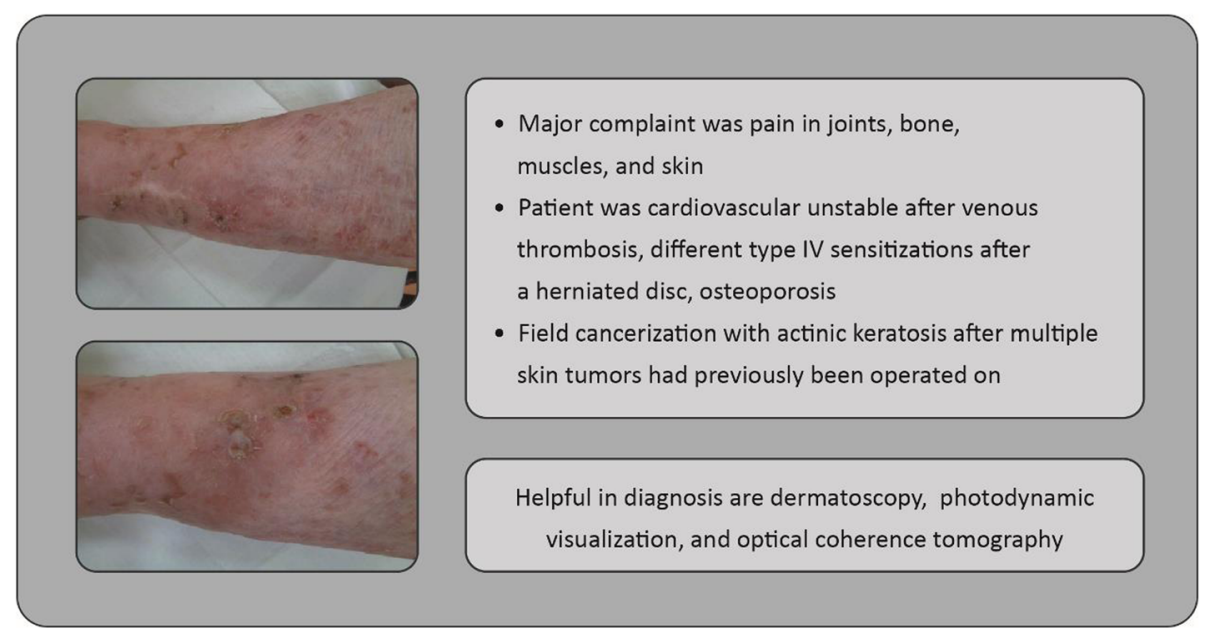

Fig. 5 Case study: 89-year-old woman presenting with multiple comorbidities (leg shown)

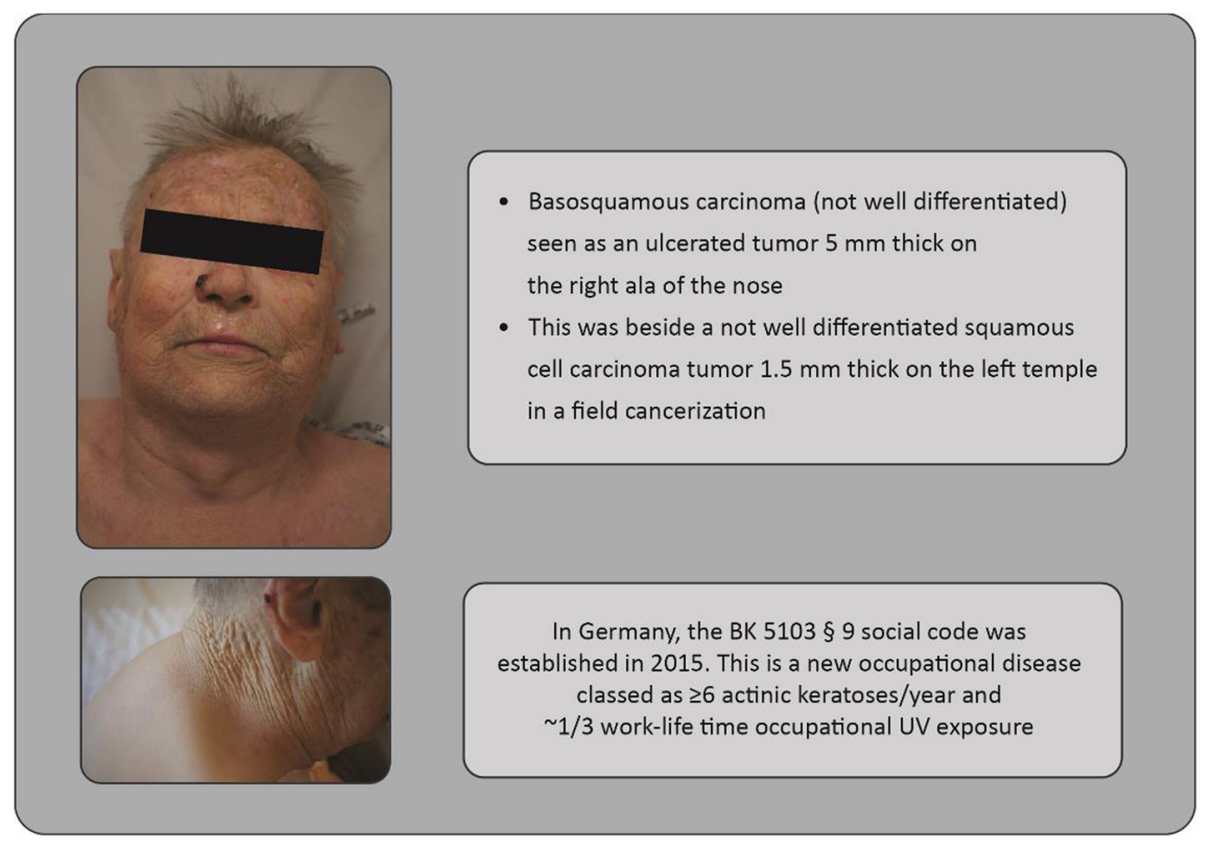

Fig. 6 Case study: field cancerization in an 80-year-old patient (head and shoulder/neck shown)

Approximately $60-65 \%$ of primary SCCs are believed to have arisen from lesions previously diagnosed clinically as actinic keratosis [41, 42], and the rate at which a specific lesion may become SCC is estimated to be a fraction of a percent over the course of a year [43]. Even when actinic keratosis lesions are classified according to their clinical appearance, there is little correlation with their histologic classification, thereby reinforcing the need to treat all actinic keratosis lesions and field cancerization [44] (see "Cyclooxygenase in Cancer Prevention and Treatments for Actinic Keratosis", by Gareth Thomas and Colin Morton, published in this Supplement, for further details on actinic keratosis treatment). While long-term efficacy and tolerance of treatments are key considerations for clinicians, comorbidities may impact treatment success. 
The broad actinic keratosis spectrum characterized by age, localization, medication, co-dermatoses, and exogenous factors (Figs. 1, 5) requires an individualized treatment approach for each patient. Figures 1, 2, 3, 4, 5, 6, 7 and 8 show examples of clinical cases. Patients who have received a kidney transplant represent a particularly challenging population. Skin tumors are a major problem in these patients, and key challenges for the clinician include treatment of the whole integument, sequential therapies, and achievement of long-term success when the patient is immunosuppressed (where inflammatory and immunomodulatory approaches are restricted). Figure 7 shows an example of a transplant patient in whom there was a suspicion of actinic keratoses in an extended field, with treatment choices being operative or destructive.

Many more therapeutic options are available for non-immunosuppressed patients. However, there is still limited availability of some medications as they are not approved for all NMSC types and localizations (Table 1). Furthermore, when extensive field cancerization encompassing the whole integument is evident, treatment must occur over a very large area of affected skin.

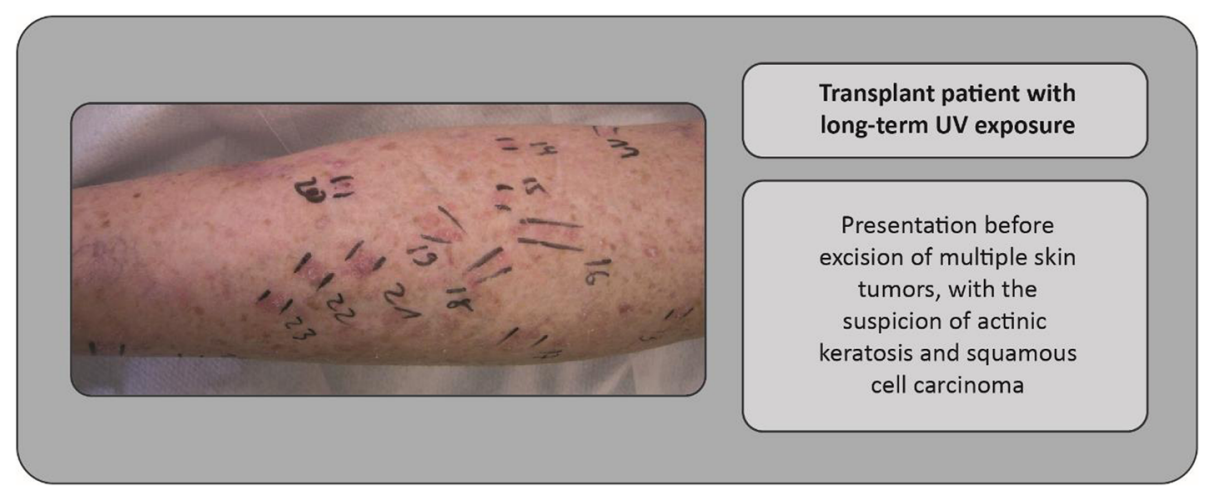

Fig. 7 Case study: Treatment of a patient who had received a kidney transplant (leg shown)

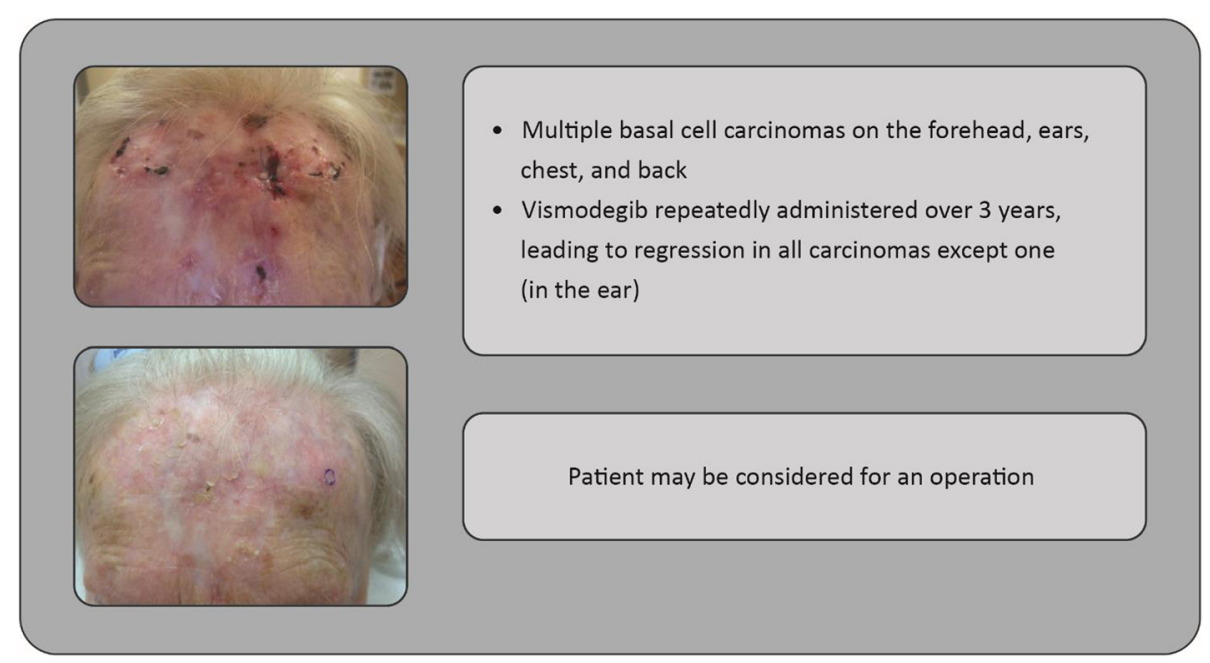

Fig. 8 Case study: 85-year-old woman with multiple basal cell carcinomas (forehead shown) 
Table 1 Recommended topical treatments for actinic keratosis

\begin{tabular}{|c|c|c|c|}
\hline Drug & EMA approval date & Approved for localization & Area \\
\hline $5 \% 5-\mathrm{FU}^{\mathrm{a}}[92]$ & 1998 & All localizations & $500 \mathrm{~cm}^{2}$ \\
\hline $\begin{array}{l}\text { 5-FU } 0.5 \% \text { with } 10 \% \text { salicylic } \\
\text { acid }^{\text {b }} \text { [93] }\end{array}$ & 2011 & All localizations & $25 \mathrm{~cm}^{2}$ (maximum of 10 lesions) \\
\hline $\begin{array}{l}\text { 3\% diclofenac with } 2.5 \% \text { hyaluronic } \\
\text { acid }^{\mathrm{b}}[94]\end{array}$ & 2000 & All localizations & Maximum of $8 \mathrm{~g} /$ day \\
\hline $5 \%$ imiquimod $^{a}[95]$ & 1998 & Head & $25 \mathrm{~cm}^{2}$ \\
\hline $3.75 \%$ imiquimod $^{a}[96]$ & 2012 & Head & $25 \mathrm{~cm}^{2}$ \\
\hline $0.05 \%$ ingenol mebutate ${ }^{c}[97]$ & 2012 & Body, extremities & $25 \mathrm{~cm}^{2}$ \\
\hline $0.015 \%$ ingenol mebutate ${ }^{c}[98]$ & 2012 & Head & $25 \mathrm{~cm}^{2}$ \\
\hline
\end{tabular}

Please refer to your local prescribing information

${ }^{a}$ MEDA (http://www.meda.co.za/)

b Almirall (http://www.almirall.com/en/)

c LEO (http://www.leo-pharma.co.uk/)

\section{Basal Cell Carcinoma}

Though the majority of patients with BCC have a good prognosis, some patients develop a more complex, advanced disease with relatively few treatment options; indeed, no formal treatment algorithms are available. However, the recent development of hedgehog signaling pathway inhibitors, such as vismodegib, has been significant, providing an effective treatment option for some patients. In particular, vismodegib treatment may be appropriate if the tumor is considered inoperable and radiation therapy is declined; complete remission is achieved in $21 \%$ of locally advanced BCC [45], even in those infiltrating adjacent muscle and bone structures. Many more cases with partial remission and shrinking tumors may be considered for operation (Fig. 8).

\section{Malignant Melanoma Stage IV}

Treatment approaches for melanoma encompass two main strategies: targeted therapies (e.g., BRAF- and MEK-inhibitors); and immunotherapies (e.g., anti-CTLA-4 and anti-PD-1).
The combination of BRAF- and MEK-inhibitors is well established in patients with tumors harboring the BRAF mutation, primarily owing to the development of tumor resistance with BRAF-inhibitor monotherapy [46]. Although this combination represents an effective option with an acceptable toxicity profile [47], questions still remain as to whether sequential or cyclic application of BRAF- and MEK-inhibitors would be more beneficial, and whether immunotherapies may represent equally useful alternatives [48].

With regard to immunotherapies, anti-PD-1 monotherapy may be preferable to anti-CLTA-4 monotherapy [49]: combining anti-PD-1 and anti-CTLA-4 therapies may increase response and remission rates. However, this may be at the risk of higher toxicity (with predominantly gastrointestinal, hepatic, and cutaneous adverse events) [50] and therefore would be most appropriate in patients with progressive disease or lower PD-L1 expression. Further studies on sequential/cyclic combinations of these immunotherapies with consideration of immunologically relevant parameters (e.g., PD-L1 expression levels, BRAF/NRAS/cKIT mutation analysis), tumor typing and staging, and patient characteristics (e.g., age, comorbidities, treatment history) are ongoing [48]. 


\section{THE SUN: FRIEND OR FOE?}

\section{The Impact of Sunlight Exposure on Health}

The impact of sunlight exposure on health is subject to debate-here, we present our views on the available evidence. Several epidemiologic studies have provided evidence for the beneficial effect of sun exposure on overall health status. All-cause mortality (death due to any cause) was inversely correlated with increased sun exposure in several studies, with a particular reduction in cardiovascular mortality. A nationwide Danish case-control study showed that having a diagnosis of skin cancer, a marker for sun exposure, was associated with a lower incidence of myocardial infarction, fewer hip fractures in those below the age of 90 years, and fewer deaths from any cause [51]. Similarly, among Swedish women, habits indicating avoidance of sun exposure were a risk factor for all-cause mortality; the mortality rate among such 'avoiders' was approximately two-fold higher compared with the highest sun exposure group [52]. It is possible that severely restricting sun exposure, particularly at locations with low solar intensity, might in fact have a negative effect on health [52].

In addition, studies have shown that blood pressure and the incidence of ischemic heart disease correlate with the latitude of a person's country of residence $[53,54]$. It is also known that blood pressure is lower during summer compared with winter [55]. This is of great significance as high blood pressure is the leading cause of disease and premature death in the world $[56,57]$.

Meta-analyses of several studies indicate that serum vitamin D levels are inversely correlated with blood pressure and the incidence of cardiovascular disease, diabetes, and hypertension [58, 59]. Furthermore, observational studies indicate that the risk of death from any cause is correlated with circulating 25-hydroxyvitamin D [60]. However, extensive studies, comprising meta-analyses of several clinical trials, have conclusively shown that oral vitamin D supplementation has no effect on blood pressure, ischemic heart disease, or stroke $[58,61]$, although vitamin D3 supplementation may reduce all-cause mortality [60]. Although vitamin D may account for some of the beneficial effects observed with sunlight exposure, it may be considered a marker of the person's occupational or recreational sun exposure.

\section{Nitric Oxide and the Skin as a Mechanism Behind the Positive Effects of Sunlight}

It has been proposed that many of the documented beneficial effects of exposure to sunlight, particularly those related to cardiovascular health, involve mechanisms unrelated to melatonin, vitamin $\mathrm{D}$, and exposure to UVB [62]. Recent studies suggest that stores of nitric oxide (NO)-related species in the skin may be particularly important in this respect. Both the skin and the dermal vasculature contain biologically significant stores of bound NO species [63]. Upon exposure of the skin to UVA, photodecomposition of these NO stores takes place and NO species are released into the circulation, resulting in arterial vasodilation, with cardioprotective and antihypertensive effects $[62,64]$. This mechanism has also been shown to suppress the development of diabetes and metabolic syndrome in a mouse model [65]. Long-term suberythemal and erythemal UV light significantly suppressed weight gain, glucose intolerance, and insulin resistance in mice fed a high-fat diet, an effect that was not reproduced by vitamin $\mathrm{D}$ supplementation. Importantly, skin induction of NO reproduced many of the effects of UV radiation [65].

\section{WHAT SHOULD A DERMATOLOGIST KNOW ABOUT HPV?}

There are several key areas in which knowledge of HPV natural history and vaccination status is important for dermatologists. Table 2 provides examples of common questions, along with evidence-based responses for each question. 
Table 2 What should the dermatologist know about HPV? Key questions and answers

Question Answer

Does every patient develop genital warts after HPV infection?

How long can HPV infections last?

Is a patient with subclinical infection contagious?

Is the patient no longer infectious once genital warts have been treated?

Is there a rationale for treating subclinical HPV infections?

What should be the advice for patients who have been treated for genital warts, but who may still have subclinical infection?

What advice should patients receive for their sexual partners concerning infection?

Is there any risk of HPV-related cancer in male patients?

Do HPV vaccines protect against other HPV genotypes that may cause genital warts?

Considering the cost of the vaccine, is there enough evidence for vaccination of already infected patients? And for their sexual partners?

Is there a rationale for HPV vaccination in young males?
Even though HPV infection is very common, very few patients will develop genital warts after infection

Up to $90 \%$ of HPV infections will clear within 2 years

Yes, but we should distinguish between subclinical and latent infections (we know very little about latent infections). subclinical infections do exist and can last for years, but they are probably only contagious when there is viral replication and shedding

Patients can be infectious even after removal/treatment of genital warts

No, what is important is the lesions, not the infection itself The important thing to focus on is the lesions; screening for early lesions, and subsequent treatment

Although there is no formal recommendation, HPV vaccination is advised among patients with a history of HPV-related lesions

The important thing to focus on is the lesions; screening for early lesions, and subsequent treatment

Although there is no formal recommendation, HPV vaccination is advised among patients with a history of HPV-related lesions

Only patients who do not resolve HPV infections are at a higher risk of HPV persistence and subsequent HPV-related diseases, including pre-cancer and cancer

Yes, they protect against HPV types 6 and 11 that cause 90\% of genital warts and recurrent respiratory papillomatosis

The current cost of HPV vaccines in national immunization programs has been reduced threefold

Yes, the vaccine will not cure current active infections but will block new infections as well as auto-inoculated virions Yes, very strong, and threefold:

1. To reduce transmission and circulation in the population

2. To protect themselves (male burden is now considerable)

3. For gender equality 


\section{Human Papillomavirus and Cancer}

More than 150 human papillomavirus (HPV) types have so far been identified. HPV falls into five genera, with the Alpha and Beta/Gamma genera representing the largest groups [66]. Mucosal HPV types from the Alpha genus are the ones associated with neoplastic disease and the most common viral infections of the reproductive tract; the World Health Organization acknowledges that most sexually active men and women will be infected at some point in their lives [67]. Twelve Alpha HPVs are classified as carcinogenic to humans and fifteen as probably/possibly carcinogenic [68]. Two HPVs, HPV 16 and 18, stand out for their carcinogenicity and contribute to approximately $70 \%$ of all HPV-related cancers worldwide [69-74]. Although most infections resolve spontaneously and the majority of women with infection do not develop cancer, a small proportion of HPV infections will persist and progress to pre-cancer and cancer [75]. Protective risk factors that reduce the risk of HPV infection and subsequent cancer include consistent condom use [76], male circumcision [77], and use of an intrauterine device [78].

The impact of the estimated contribution of HPV to cancer from an epidemiologic point of view is larger than previously thought. Indeed, HPV infection can be considered a pandemic disease for several reasons [79]. Firstly, it is universal and widespread, occurring on all continents, in both women and men, among young people and adults, and across most races and socioeconomic groups. Secondly, it is extensive, as it causes a variety of related diseases, both pre-cancerous and cancerous, involving a wide range of anatomic sites. Finally, the epidemiology of HPV is dynamic, as opposed to stable, with increasing rates of infection and disease.

\section{The Role of HPV in Skin Cancer}

Some studies suggest that a particular genus, the $\beta$ HPVs, may play a role in the pathogenesis of NMSC [80], though this role has not been well studied. However, the association of $\beta$ HPV infection with NMSC in patients with a very rare, genetically determined condition, epidermodysplasia verruciformis, has been well established [81]. In stark contrast to $\alpha$ HPV-associated cancers (such as cervical cancer, as discussed above), the presence of $\beta$-HPV DNA does not appear to be essential for the maintenance of the malignant phenotype [82].

\section{Prevention Through Vaccination Strategies}

Three HPV vaccines are commercially available including a bivalent form against HPV types 16 and 18, a quadrivalent form against HPV types 6, 11, 16 and 18, and a 9-valent form against types $6,11,16,18,31$, $33,45,52$ and 58 [83]. Persistent infection with high-risk HPV types 16 and 18 is responsible for the majority of cervical cancer worldwide, whereas low-risk types 6 and 11 are responsible for most genital warts [84]. The vaccines are highly efficacious, immunogenic and safe in the prevention of pre- and neoplastic cervical-, vulvar-, vaginalor anal-related disease in women [85-87]. The quadrivalent HPV vaccine has been shown to be effective against genital warts $[88,89]$ and anal precancerous lesions [90]. As well as being associated with wart formation, cutaneous papillomaviruses can lead to the development of NMSC, but further research with HPV vaccines is needed to assess their efficacy in preventing NMSC.

Data from multiple countries have shown a clear impact in the reduction of HPV infections and related conditions within a few years of vaccine introduction [91], and pediatricians, gynecologists, primary healthcare professionals, clinicians, and public health officials, as well as dermatologists, have all played a key role in achieving this wide vaccination coverage.

This article is based on previously conducted studies, and does not involve any new studies of human or animal subjects performed by any of the authors. 


\section{ACKNOWLEDGEMENTS}

Sponsorship and article processing charges for this supplement were funded by Almirall S.A. This article is based on presentations from the 9th Skin Academy Symposium, April 9-10, 2016, Barcelona, Spain, sponsored by Almirall S.A. All named authors meet the International Committee of Medical Journal Editors (ICMJE) criteria for authorship for this manuscript, take responsibility for the integrity of the work as a whole, and have given final approval to the version to be published. We thank Dr Laia Bruni for her advice and contribution to this manuscript, on behalf of Dr Castellsagué, upon his passing. All images (figures) provided courtesy of Dorothée Nashan with full patient consent. Medical writing support was provided by Chrissie Kouremenou of Complete Medical Communications, funded by Almirall S.A.

Disclosures. Zoe Apalla has received honoraria from Almirall S.A. and Leo Pharma. Dorothée Nashan has received honoraria from Almirall S.A., BMS, MEDA, MSD, Novartis, and Roche. Richard B Weller has acted as a consultant for AOBiome and Novartis; has been on the Speakers' Bureaux for Almirall S.A. and Johnson and Johnson; has received honoraria from Johnson and Johnson and Novartis; and is an employee and stockholder of Relaxsol Ltd. Xavier Castellsagué has received occasional honoraria for lecturing from Almirall S.A., Merck, SPMSD, and Vianex, and has received funding for institutional research from Genticel, GSK, Merck, and SPMSD.

Compliance with Ethics Guidelines. This article is based on previously conducted studies, and does not involve any new studies of human or animal subjects performed by any of the authors. Informed consent was obtained from all patients for which identifying information is included in this article.

Data Availability. Data sharing is not applicable to this article as no datasets were generated or analyzed during the current study.
Open Access. This article is distributed under the terms of the Creative Commons Attribution-NonCommercial 4.0 International License (http://creativecommons.org/licenses/ by-nc/4.0/), which permits any noncommercial use, distribution, and reproduction in any medium, provided you give appropriate credit to the original author(s) and the source, provide a link to the Creative Commons license, and indicate if changes were made.

\section{REFERENCES}

1. Whiteman DC, Green AC, Olsen CM. Growing burden of invasive melanoma: projections of incidence rates and numbers of new cases in six susceptible populations through 2031. J Invest Dermatol. 2016;136:1161-71.

2. De Vries E, Coebergh JW. Cutaneous malignant melanoma in Europe. Eur J Cancer. 2004;40:2355-66.

3. Lasithiotakis K, Kruger-Krasagakis S, Manousaki A, Ioannidou D, Panagiotides I, Tosca A. The incidence of cutaneous melanoma on Crete, Greece. Int J Dermatol. 2006;45:397-401.

4. Mansson-Brahme E, Johansson $\mathrm{H}$, Larsson O, Rutqvist LE, Ringborg U. Trends in incidence of cutaneous malignant melanoma in a Swedish population 1976-1994. Acta Oncol. 2002;41:138-46.

5. Stang A, Pukkala E, Sankila R, Soderman B, Hakulinen T. Time trend analysis of the skin melanoma incidence of Finland from 1953 through 2003 including 16,414 cases. Int J Cancer. 2006;119:380-4.

6. Ulmer MJ, Tonita JM, Hull PR. Trends in invasive cutaneous melanoma in Saskatchewan 1970-1999. J Cutan Med Surg. 2003;7:433-42.

7. Dennis LK. Analysis of the melanoma epidemic, both apparent and real: data from the 1973 through 1994 surveillance, epidemiology, and end results program registry. Arch Dermatol. 1999;135:275-80.

8. Geller AC, Miller DR, Annas GD, Demierre MF, Gilchrest BA, Koh HK. Melanoma incidence and mortality among US whites, 1969-1999. JAMA. 2002;288:1719-20.

9. Hall HI, Miller DR, Rogers JD, Bewerse B. Update on the incidence and mortality from melanoma in the United States. J Am Acad Dermatol. 1999;40:35-42. 
10. Perera E, Gnaneswaran N, Staines C, Win AK, Sinclair R. Incidence and prevalence of non-melanoma skin cancer in Australia: a systematic review. Australas J Dermatol. 2015;56:258-67.

11. American Cancer Society. Cancer Facts \& Figures 2016. http://www.cancer.org/acs/groups/ content/@research/documents/document/acspc-04 7079.pdf. Accessed 2 Aug 2016.

12. National Cancer Institute. SEER Stats Fact Sheets: Melanoma of the skin. http://seer.cancer.gov/ statfacts/html/melan.html. Accessed 13 July 2016.

13. Monshi B, Vujic M, Kivaranovic D, et al. The burden of malignant melanoma-lessons to be learned from Austria. Eur J Cancer. 2016;56:45-53.

14. Erdmann F, Lortet-Tieulent J, Schuz J, et al. International trends in the incidence of malignant melanoma 1953-2008-are recent generations at higher or lower risk? Int J Cancer. 2013;132:385-400.

15. Linos E, Swetter SM, Cockburn MG, Colditz GA, Clarke CA. Increasing burden of melanoma in the United States. J Invest Dermatol. 2009;129:1666-74.

16. Shaikh WR, Dusza SW, Weinstock MA, Oliveria SA, Geller AC, Halpern AC. Melanoma thickness and survival trends in the United States, 1989 to 2009. J Natl Cancer Inst. 2016;108:pii-djv294.

17. Higgins HW, Lee KC, Galan A, Leffell DJ. Melanoma in situ: part I. Epidemiology, screening, and clinical features. J Am Acad Dermatol. 2015;73:181-90.

18. Frangos JE, Duncan LM, Piris A, et al. Increased diagnosis of thin superficial spreading melanomas: a 20-year study. J Am Acad Dermatol. 2012;67:387-94.

19. Welch HG, Woloshin S, Schwartz LM. Skin biopsy rates and incidence of melanoma: population based ecological study. BMJ. 2005;331:481.

20. Katalinic A, Kunze U, Schafer T. Epidemiology of cutaneous melanoma and non-melanoma skin cancer in Schleswig-Holstein, Germany: incidence, clinical subtypes, tumour stages and localization (epidemiology of skin cancer). Br J Dermatol. 2003;149:1200-6.

21. Diepgen TL, Mahler V. The epidemiology of skin cancer. Br J Dermatol. 2002;146:1-6.

22. Leiter U, Garbe C. Epidemiology of melanoma and nonmelanoma skin cancer-the role of sunlight. Adv Exp Med Biol. 2008;624:89-103.
23. Eide MJ, Krajenta R, Johnson D, et al. Identification of patients with nonmelanoma skin cancer using health maintenance organization claims data. Am J Epidemiol. 2010;171:123-8.

24. Fransen M, Karahalios A, Sharma N, English DR, Giles GG, Sinclair RD. Non-melanoma skin cancer in Australia. Med J Aust. 2012;197:565-8.

25. Wu X, Elkin EE, Marghoob AA. Burden of basal cell carcinoma in USA. Future Oncol. 2015;11:2967-74.

26. Mudigonda T, Pearce DJ, Yentzer BA, Williford P, Feldman SR. The economic impact of non-melanoma skin cancer: a review. J Natl Compr Canc Netw. 2010;8:888-96.

27. Qureshi AA, Wei-Passanese EX, Li T, Han J. Host risk factors for the development of multiple non-melanoma skin cancers. J Eur Acad Dermatol Venereol. 2013;27:565-70.

28. Rubin AI, Chen EH, Ratner D. Basal-cell carcinoma. N Engl J Med. 2005;353:2262-9.

29. Flohil SC, Seubring I, van Rossum MM, Coebergh JW, De Vries E, Nijsten T. Trends in basal cell carcinoma incidence rates: a 37-year Dutch observational study. J Invest Dermatol. 2013;133:913-8.

30. Wehner MR, Shive ML, Chren MM, Han J, Qureshi AA, Linos E. Indoor tanning and non-melanoma skin cancer: systematic review and meta-analysis. BMJ. 2012;345:e5909.

31. Argenziano G, Zalaudek I, Hofmann-Wellenhof R, et al. Total body skin examination for skin cancer screening in patients with focused symptoms. J Am Acad Dermatol. 2012;66:212-9.

32. Argenziano G, Giacomel J, Zalaudek I, et al. Twenty nevi on the arms: a simple rule to identify patients younger than 50 years of age at higher risk for melanoma. Eur J Cancer Prev. 2014;23:458-63.

33. Giavedoni P, Puig S, Carrera C. Noninvasive imaging for nonmelanoma skin cancer. Semin Cutan Med Surg. 2016;35:31-41.

34. Menge TD, Pellacani G. Advances in noninvasive imaging of melanoma. Semin Cutan Med Surg. 2016;35:18-24.

35. Deinlein T, Richtig G, Schwab C, et al. The use of dermatoscopy in diagnosis and therapy of nonmelanocytic skin cancer. J Dtsch Dermatol Ges. 2016;14:144-51.

36. Di Carlo A, Elia F, Desiderio F, Catricala C, Solivetti FM, Laino L. Can video thermography improve differential diagnosis and therapy between 
basal cell carcinoma and actinic keratosis? Dermatol Ther. 2014;27:290-7.

37. Ulrich $\mathrm{M}$, Themstrup $\mathrm{L}$, de Carvalho $\mathrm{N}$, et al. Dynamic optical coherence tomography in dermatology. Dermatology. 2016;232:298-311.

38. Nashan D, Dirschka T. Aktinische Keratosen. Der Fokus verlagert sich hin $\mathrm{zu}$ einer feldgerichteten Therapie. Dtsch Dermatol. 2014;62:42-7.

39. Werner RN, Stockfleth E, Connolly SM, et al. Evidenceand consensus-based (S3) Guidelines for the Treatment of Actinic Keratosis-International League of Dermatological Societies in cooperation with the European Dermatology Forum-Short version. J Eur Acad Dermatol Venereol. 2015;29:2069-79.

40. Glogau RG. The risk of progression to invasive disease. J Am Acad Dermatol. 2000;42:23-4.

41. Criscione VD, Weinstock MA, Naylor MF, Luque C, Eide MJ, Bingham SF. Actinic keratoses: natural history and risk of malignant transformation in the Veterans Affairs Topical Tretinoin Chemoprevention Trial. Cancer. 2009;115:2523-30.

42. Marks R, Rennie G, Selwood TS. Malignant transformation of solar keratoses to squamous cell carcinoma. Lancet. 1988;1:795-7.

43. Dodson JM, DeSpain J, Hewett JE, Clark DP. Malignant potential of actinic keratoses and the controversy over treatment. A patient-oriented perspective. Arch Dermatol. 1991;127:1029-31.

44. Schmitz L, Kahl P, Majores M, Bierhoff E, Stockfleth E, Dirschka T. Actinic keratosis: correlation between clinical and histological classification systems. J Eur Acad Dermatol Venereol. 2016;30:1303-7.

45. Sekulic A, Migden MR, Oro AE, et al. Efficacy and safety of vismodegib in advanced basal-cell carcinoma. N Engl J Med. 2012;366:2171-9.

46. Eroglu Z, Ribas A. Combination therapy with BRAF and MEK inhibitors for melanoma: latest evidence and place in therapy. Ther Adv Med Oncol. 2016;8:48-56.

47. Dhillon S. Dabrafenib plus trametinib: a review in advanced melanoma with a BRAF (V600) mutation. Target Oncol. 2016;11:417-28.

48. Atkins MB, Larkin J. Immunotherapy combined or sequenced with targeted therapy in the treatment of solid tumors: current perspectives. J Natl Cancer Inst. 2016;108:djv414.
49. Long $\mathrm{G}$, et al. A phase $1 / 3$ multicenter trial of talimogene laherparepvec in combination with pembrolizumab for unresected, stage IIIB-IV melanoma (MASTERKEY-265). J Clin Oncol. 2016;34(Suppl):abstr TPS9598.

50. Marrone KA, Ying W, Naidoo J. Immune-related adverse events from immune checkpoint inhibitors. Clin Pharmacol Ther. 2016;100:242-51.

51. Brondum-Jacobsen P, Nordestgaard BG, Nielsen SF, Benn M. Skin cancer as a marker of sun exposure associates with myocardial infarction, hip fracture and death from any cause. Int $\mathrm{J}$ Epidemiol. 2013;42:1486-96.

52. Lindqvist PG, Epstein E, Landin-Olsson $\mathrm{M}$, et al. Avoidance of sun exposure is a risk factor for all-cause mortality: results from the Melanoma in Southern Sweden cohort. J Intern Med. 2014;276:77-86.

53. Zittermann A. Vitamin D and disease prevention with special reference to cardiovascular disease. Prog Biophys Mol Biol. 2006;92:39-48.

54. Imperial College London School of Public Health. Country trends in metabolic risk factors. https:// www1.imperial.ac.uk/publichealth/departments/ebs/ projects/eresh/majidezzati/healthmetrics/metaboli criskfactors/metabolic_risk_factor_maps/. Accessed 2 Aug 2016.

55. Brennan PJ, Greenberg G, Miall WE, Thompson SG. Seasonal variation in arterial blood pressure. Br Med J (Clin Res Ed). 1982;285:919-23.

56. Lim SS, Vos T, Flaxman AD, et al. A comparative risk assessment of burden of disease and injury attributable to 67 risk factors and risk factor clusters in 21 regions, 1990-2010: a systematic analysis for the global burden of disease study 2010 . Lancet. 2012;380:2224-60.

57. Murray CJ, Ezzati M, Flaxman AD, et al. GBD 2010: design, definitions, and metrics. Lancet. 2012;380:2063-6.

58. Pittas AG, Chung M, Trikalinos $\mathrm{T}$, et al. Systematic review: vitamin $\mathrm{D}$ and cardiometabolic outcomes. Ann Intern Med. 2010;152:307-14.

59. Parker J, Hashmi O, Dutton D, et al. Levels of vitamin $\mathrm{D}$ and cardiometabolic disorders: systematic review and meta-analysis. Maturitas. 2010;65:225-36.

60. Chowdhury R, Kunutsor S, Vitezova A, et al. Vitamin $\mathrm{D}$ and risk of cause specific death: 
systematic review and meta-analysis of observational cohort and randomised intervention studies. BMJ. 2014;348:g1903.

61. Bolland MJ, Grey A, Gamble GD, Reid IR. The effect of vitamin D supplementation on skeletal, vascular, or cancer outcomes: a trial sequential meta-analysis. Lancet Diabetes Endocrinol. 2014;2:307-20.

62. Feelisch M, Kolb-Bachofen V, Liu D, et al. Is sunlight good for our heart? Eur Heart J. 2010;31:1041-5.

63. Mowbray M, McLintock S, Weerakoon $\mathrm{R}$, et al. Enzyme-independent NO stores in human skin: quantification and influence of UV radiation. J Invest Dermatol. 2009;129:834-42.

64. Liu D, Fernandez BO, Hamilton A, et al. UVA irradiation of human skin vasodilates arterial vasculature and lowers blood pressure independently of nitric oxide synthase. J Invest Dermatol. 2014;134:1839-46.

65. Geldenhuys S, Hart PH, Endersby R, et al. Ultraviolet radiation suppresses obesity and symptoms of metabolic syndrome independently of vitamin D in mice fed a high-fat diet. Diabetes. 2014;63:3759-69.

66. Doorbar J, Egawa N, Griffin H, Kranjec C, Murakami I. Human papillomavirus molecular biology and disease association. Rev Med Virol. 2015;25(Suppl 1):2-23.

67. World Health Organization. Human papillomavirus (HPV) and cervical cancer fact sheet. http:// www.who.int/mediacentre/factsheets/fs380/en/\#. Accessed 2 Aug 2016.

68. Bouvard V, Baan $\mathrm{R}$, Straif $\mathrm{K}$, et al. A review of human carcinogens-part B: biological agents. Lancet Oncol. 2009;10:321-2.

69. de Sanjose S, Quint WG, Alemany L, et al. Human papillomavirus genotype attribution in invasive cervical cancer: a retrospective cross-sectional worldwide study. Lancet Oncol. 2010;11:1048-56.

70. de Sanjose S, Alemany L, Ordi J, et al. Worldwide human papillomavirus genotype attribution in over 2000 cases of intraepithelial and invasive lesions of the vulva. Eur J Cancer. 2013;49:3450-61.

71. Alemany L, Saunier M, Tinoco L, et al. Large contribution of human papillomavirus in vaginal neoplastic lesions: a worldwide study in 597 samples. Eur J Cancer. 2014;50:2846-54.

72. Alemany L, Saunier M, varado-Cabrero I, et al. Human papillomavirus DNA prevalence and type distribution in anal carcinomas worldwide. Int J Cancer. 2015;136:98-107.

73. Castellsague X, Alemany L, Quer M, et al. HPV Involvement in Head and Neck Cancers: Comprehensive Assessment of Biomarkers in 3680 Patients. J Natl Cancer Inst. 2016;108: djv403.

74. Alemany L, Cubilla A, Halec G, et al. Role of Human Papillomavirus in Penile Carcinomas Worldwide. Eur Urol. 2016;69:953-61.

75. Moscicki AB, Schiffman M, Burchell A, et al. Updating the natural history of human papillomavirus and anogenital cancers. Vaccine. 2012;30(Suppl 5):F24-33.

76. Winer RL, Hughes JP, Feng Q, et al. Condom use and the risk of genital human papillomavirus infection in young women. $\mathrm{N}$ Engl J Med. 2006;354:2645-54.

77. Castellsague X, Bosch FX, Munoz N, et al. Male circumcision, penile human papillomavirus infection, and cervical cancer in female partners. N Engl J Med. 2002;346:1105-12.

78. Castellsague $\mathrm{X}$, Diaz $\mathrm{M}$, Vaccarella $\mathrm{S}$, et al. Intrauterine device use, cervical infection with human papillomavirus, and risk of cervical cancer: a pooled analysis of 26 epidemiological studies. Lancet Oncol. 2011;12:1023-31.

79. Bosch FX, Broker TR, Forman D, et al. Comprehensive control of human papillomavirus infections and related diseases. Vaccine. 2013;31(Suppl 7):H1-31.

80. Zakrzewska K, Regalbuto E, Pierucci F, et al. Pattern of HPV infection in basal cell carcinoma and in perilesional skin biopsies from immunocompetent patients. Virol J. 2012;9:309.

81. Borgogna C, Zavattaro E, De Andrea M, et al. Characterization of beta papillomavirus E4 expression in tumours from Epidermodysplasia Verruciformis patients and in experimental models. Virology. 2012;423:195-204.

82. McLaughlin-Drubin ME. Human papillomaviruses and non-melanoma skin cancer. Semin Oncol. 2015;42:284-90.

83. National Center for Respiratory Diseases. HP vaccine information for clinicians. https://www. cdc.gov/hpv/hcp/need-to-know.pdf. Accessed 2 Aug 2016.

84. Bosch FX. HPV vaccines and cervical cancer. Ann Oncol. 2008;19(Suppl 5):v48-51. 
85. Lehtinen M, Paavonen J, Wheeler CM, et al. Overall efficacy of HPV-16/18 AS04-adjuvanted vaccine against grade 3 or greater cervical intraepithelial neoplasia: 4-year end-of-study analysis of the randomised, double-blind PATRICIA trial. Lancet Oncol. 2012;13:89-99.

86. Dillner J, Kjaer SK, Wheeler CM, et al. Four year efficacy of prophylactic human papillomavirus quadrivalent vaccine against low grade cervical, vulvar, and vaginal intraepithelial neoplasia and anogenital warts: randomised controlled trial. BMJ. 2010;341:c3493.

87. Joura EA, Giuliano AR, Iversen OE, et al. A 9-valent HPV vaccine against infection and intraepithelial neoplasia in women. N Engl J Med. 2015;372:711-23.

88. Giuliano AR, Palefsky JM, Goldstone S, et al. Efficacy of quadrivalent HPV vaccine against HPV Infection and disease in males. $\mathrm{N}$ Engl J Med. 2011;364:401-11.

89. Luna J, Plata M, Gonzalez M, et al. Long-term follow-up observation of the safety, immunogenicity, and effectiveness of Gardasil in adult women. PLoS ONE. 2013;8:e83431.

90. Palefsky JM, Giuliano AR, Goldstone S, et al. HPV vaccine against anal HPV infection and anal intraepithelial neoplasia. $\mathrm{N}$ Engl $\mathrm{J}$ Med. 2011;365:1576-85.

91. Drolet M, Benard E, Boily MC, et al. Population-level impact and herd effects following human papillomavirus vaccination programmes: a systematic review and meta-analysis. Lancet Infect Dis. 2015;15:565-80.

92. EMC. Efudix cream summary of product characteristics. http://www.medicines.org.uk/ EMC/medicine/6219. Accessed 2 Aug 2016.

93. EMC. Actikerall $5 \mathrm{mg} / \mathrm{g}+100 \mathrm{mg} / \mathrm{g}$ cutaneous solution summary of product characteristics. http://www.medicines.org.uk/emc/medicine/24614. Accessed 2 Aug 2016.

94. EMC. Solaraze summary of product characteristics. http://www.medicines.org.uk/EMC/medicine/21229. Accessed 2 Aug 2016.

95. EMC. Aldara 5\% cream summary of product characteristics. http://www.medicines.org.uk/ EMC/medicine/8. Accessed 2 Aug 2016.

96. EMC. Zyclara $3.75 \%$ cream summary of product characteristics. https://www.medicines.org.uk/emc/ medicine/27323. Accessed 2 Aug 2016.

97. EMC. Picato $500 \mathrm{mcg} / \mathrm{g}$ gel summary of product characteristics. https://www.medicines.org.uk/emc/ medicine/27247. Accessed 2 Aug 2016.

98. EMC. Picato $150 \mathrm{mcg} / \mathrm{g}$ gel summary of product characteristics. http://www.medicines.org.uk/emc/ medicine/27246. Accessed 2 Aug 2016. 